\title{
Modelling Gardens as Social-ecological Systems Using Geodata: The Example of Watering and Landscaping of Urban Ecosystems
}

\author{
Angela Hof \\ Department of Geography, Salzburg University, Austria · angela.hof@sbg.ac.at
}

Full paper double blind review

\begin{abstract}
The paper discusses conceptual aspects of modelling gardens as urban social-ecological systems. These conceptual aspects build on previous research, and extend previous research into the nexus of urbanisation dynamics, through changing lifestyles, new aesthetics of urban nature, and the resulting landscape and garden design in urban residential areas that are causally related to changing urban water demand patterns. The focus of modelling gardens as social-ecological systems described here is on the ecological subsystem, and the links to the human subsystem, as formalized by the framework of urban ecosystem services. The paper presents and discusses theoretical and conceptual approaches to understanding and formalizing the spatial patterns of urban vegetated cooling as an ecosystem service, and to link this with an assessment of the potential water requirements to supply these services. Another link is through the impacts of gardens on urban biodiversity. Like parks, gardens are horticultural, 'novel urban ecosystems' that have potentially positive effects on urban biodiversity. This aspect is discussed here, but not explicitly included in the conceptual modelling approach. The pivotal role of geodata for modelling gardens as social-ecological systems is demonstrated in two respects: First, by describing the necessity to map relevant urban design features at high levels of detail, which can be achieved with object-oriented classification approaches applied to very high-resolution satellite imagery. Second, the framework concept of ecosystem services is discussed, reiterating why ecosystem services are spatially dependent. It is argued that the ecosystem services concept cannot be applied in a meaningful way if space and location as a framework for analysis, understanding, and presentation of results are neglected. The final section of the paper illustrates the use of the social-ecological systems and urban ecosystem services frameworks in conceptual modelling applied to the research question of understanding how garden management decisions contribute to thermally pleasant residential landscapes.
\end{abstract}

\section{Introduction}

\subsection{Understanding the Importance of Gardens as Social-ecological Systems}

Discourses on urban development now widely reflect an acceptance that urban green spaces contribute to all three dimensions - social, economic, and environmental - of urban sustainability. Strategies aiming at sustainable development, liveability, and resilience in urban

GI_Forum - Journal for Geographic Information Science, 1-2015.

(C) Herbert Wichmann Verlag, VDE VERLAG GMBH, Berlin/Offenbach. ISBN 978-3-87907-558-4.

(C) ÖAW Verlag, Wien. ISSN 2308-1708, doi:10.1553/giscience2015s614. 
areas are increasingly using the framework concept of ecosystem services for analyzing social-ecological systems, and for highlighting the importance of ecosystem functions for human life (HAASE et al. 2014). The ecosystem services framework is an assessment and evaluation structure that links basic ecological structures and processes to constituents of human wellbeing. It can be seen as a bridging concept between societal and environmental systems, and between natural and social sciences (GRUNEWALD \& BASTIAN 2012). Urban research discourses start from the premise that urbanization as a global megatrend continues to increase urban areas, and to concentrate population therein. Therefore, the chain of reasoning always includes the argument that the ecosystem services concept is becoming important for urban ecosystems, too. Hence, the focus of current sustainability research on urban ecosystem services is on urban green spaces as ecosystem service providing units (compare HAASE et al. 2014). Their review shows that forest areas, land use mixtures or urban green infrastructure (parks, leisure areas) and the associated regulating ecosystem services like carbon sequestration and storage, the regulation of air temperatures, air pollution removal, and/or storm water runoff, are the focus of about half of published research on urban ecosystem services. Among the challenges of urbanization and management of ecosystems are the mismatches between spatial and temporal scales of ecological processes on the one hand, and social scales of monitoring and decision making on the other hand (BREUSTE et al. 2013). With respect to urban ecosystem services, this is one of the starting points of the paper to extend own previous research.

Two thirds of people in developed regions live in urban areas, and $40 \%$ of urban land area is used for homes and their outdoor surroundings. Across geographical locations and spatial scales, large parts of urban areas are residential landscapes that are privately managed. This has repercussions for land use and land cover, and the ecology in cities. In European and North American cities, up to $80 \%$ of the urban green spaces are privately owned, and the number of managers of these urban ecosystems is in the order of magnitude of hundreds of thousands (COOK et al. 2012, GASTON et al. 2013, GODDARD et al. 2009). Private stewardship of the land is an important bottom-up control mechanism for the provision of urban ecosystem services. It has been shown that socio-economic factors, behavioural attitudes, and value systems influence gardening practices and landscape aesthetics. Top-down control mechanisms like land-use change, urban design, and planning, are also in effect. Consequently, ownership patterns present great challenges to the sustainable development of urban ecosystems, and especially of urban green spaces. There are a large number of land owners and tenants involved that are generally not managing their land and outdoor area for ecosystem services provision, but for alternative, and often conflicting goals (GASTON et al. 2013). For example, lawns cover a larger extent of land than any other irrigated crop in the US, and are expected to extend in coming decades. Despite water scarcity in many cities, up to half the water used at home is used outside, and most of that is for watering lawns (Milesi et al. 2005, POLSKY et al. 2014). Within residential landscapes, gardens are the most important and most common setting of human-environment interactions. Especially gardens with turf grass are highly managed ecosystems that have impacts on local and regional carbon, nitrogen, phosphorus, and water flows and cycling (COOK et al. 2012, POLSKY et al. 2014). Homeowners and neighbourhoods create aesthetically- and thermallypleasant outdoor environments. They work their gardens to ensure a sustainable and continued availability of ecosystem functions from which they derive ecosystem services, albeit without necessarily being aware of the concept. Cultural ecosystem services (sense of place, social cohesion, recreation, property values), regulating ecosystem services (thermal 
comfort, water fluxes through evapotranspiration), and supporting and provisioning services (biodiversity, habitat for flora and fauna) are connected to ecological functions of gardens in residential landscapes (COOK et al. 2012).

\subsection{Site-specific Benefits People Obtain from Urban Ecosystems}

Confusion prevails in the literature on the issue which of the many underlying ecosystem processes should be termed services, and it suffices here to say that the use of the terminology is often imprecise. However, definitions like "urban ecosystems services are the benefits people obtain from urban ecosystems" (GóMEZ-BAGGETHUN et. al 2013, 179) implicitly underscore the spatial character of ecosystem services and the fact that they are sitespecific. This has been logically explained in an influential paper on environmental accounting for measuring the contributions of nature to human welfare (BOYD \& BANZHAF 2007). The authors' chain of reasoning is as follows: Unlike manufactured goods, e.g. cars, which can be transported by buyers and sellers, ecosystem services do not allow for spatial arbitrage. In turn, this means that the benefit or social value of the ecological service is spatially explicit. If the benefit is to be measured and is spatially explicit, the service's units must be spatially explicit. Hence, the ecosystem service units can be expressed both numerically and visually via Geographic Information Systems (GIS).

\subsection{Spatial Dependency of Social-ecological Properties and Functions, and Ecosystem Services}

The meaningful integration of the ecosystem services approach into urban stewardship requires the demonstration of its small-scale applicability at site level. Managing urban ecosystems for goods and services involves both information about complex human drivers at multiple scales that influence management practices, and the feedbacks with biophysical characteristics of residential landscapes. Site-specific ecological properties like vegetated ground or canopy cover, and emergent social-ecological properties such as turf grass maintenance even in arid urban environments, are direct results of main management factors like irrigation and fertilization. They are therefore indicators in the analysis of residential landscapes as social-ecological systems. Understanding private gardens as urban social-ecological systems is a prerequisite for modelling these systems. Residential landscapes as social-ecological systems have a societal subsystem and an ecological subsystem. They exhibit path-dependencies and reflect management decisions. This means that in order to fully understand the services delivered by an ecosystem, relevant stakeholders benefitting from or affecting the ecosystem must be identified, and their impact on the ecosystem considered in the assessment (COOK et al. 2012). Urban form and land cover are understood as structural elements that drive or constrain human-environment interactions and processes. Understanding and modelling gardens therefore needs to include the spatial detail required to analyse human-environment interactions, and to assess and value spatially dependent social-ecological properties and functions, and ecosystem services. 


\section{Using Geodata to Analyse the Contribution of Gardens to the Watering and Landscaping of Urban Ecosystems}

Gardens as part of urban green spaces are important elements of the urban landscape, but they also distinctively contribute to the landscaping of the urban. The social value of ecosystem services is spatially explicit, and the services have important place-based quality differences. Generally, ecosystem services are countable and mapable via GIS (BOYD \& BANZHAF 2007). Consequently, such environmental applications of geodata require first of all geodata that are fit for purpose. This can be realised by targeted mapping (BOYD \& FOODY 2011) of more specific and detailed classes such as turf, shrubs, and trees from remote sensing imagery. With targeted mapping, remote sensing is used as a source of environmental information for specific ecological research. The image analysis attention is focused on just the class(es) of interest, especially when they are rare and embedded in a mosaic of many classes, which is often the case in urban remote sensing applications. Analyses of the contribution of gardens to the watering of the urban are an entry point into complex analyses of the benefits owners and tenants obtain from gardens as urban ecosystems. The following sections outline geodata, remote sensing, and ancillary data analyses to describe the ecological subsystem of gardens as social-ecological systems.

\subsection{Assessing Water Input into Gardens}

Water input is maintaining garden vegetation at least in some months per year, or even all year-round. Through plant growth and vegetated ground or canopy cover, causally related ecosystem services include air pollutant removal, carbon sequestration and storage (regulating and supporting), and habitat and biodiversity (provisioning) services. Cooling air around homes is a regulating ecosystem service that is related to water fluxes through the soil, plant, and atmosphere system.

\subsection{Object-oriented Analysis of High-resolution Satellite Data}

The geodata used for the modelling are a final mapping product derived from remote sensing image analysis of WorldView-2 satellite data, that delivered a GIS (Geographic Information Systems)-ready vector layer containing polygons, which are labelled according to the four mapped land cover classes: swimming pools, turf grass and tree/shrub vegetation (HOF \& WOLF 2014). Object-based feature extraction was applied to generate spatial information layers as additional input features (predictor variables) for supervised per-pixel classification. Object-based features and spatial or spatial-spectral approaches are considered to be of value for urban applications, as they also consider the structural or contextual information inherent in images, and are capable of overcoming the limitations of conventional supervised per-pixel analysis approaches that rely on the spectral information alone. It was shown in other research that a combined input space, incorporating both spectral and spatial image features, can notably improve classification accuracy, provided that an adequate learning algorithm capable of handling complexity is used (WOLF 2013). 


\subsection{Assessment of Gardens' Contributions to Watering of Urban Ecosys- tems: Estimating the Evapotranspiration and the Water Requirements of Garden Landscaping}

Evapotranspiration of urban vegetation is the fundamental ecological process underlying climate regulation as an urban ecosystem service. The process-relevant water fluxes can be measured with sophisticated methods and setups of measurement equipment, but the Water Use Classification of Landscape Plants (WUCOLS) method developed by CosTELLO et al. (2000) is a practical approach that can provide a realistic estimate of the total amount of water lost through evapotranspiration (NOURI et al. 2013). This estimate equals the amount of water that should be partially or fully replaced by irrigation. According to WUCOLS principles and as outlined by NOURI et al. $(2013,251)$, urban landscape evapotranspiration $\left(\mathrm{ET}_{\mathrm{L}}\right)$ is a function of a landscape coefficient $\left(\mathrm{K}_{\mathrm{L}}\right)$ and reference evapotranspiration $\left(\mathrm{ET}_{0}\right)$, as shown in Equation (1)

Equation 1: $\quad \mathrm{ET}_{\mathrm{L}}=\mathrm{K}_{\mathrm{L}} \times \mathrm{ET}_{0}$

The urban landscape evapotranspiration rate for any landscaping and species assemblage in gardens can be readily calculated from the reference evapotranspiration and the landscape coefficient. This is conceptually similar to the determination of crop water requirements in agriculture, using Penman-Monteith reference evapotranspiration $\left(\mathrm{ET}_{0}\right)$ multiplied by a species factor determined for the crop. For estimating evapotranspiration of landscape plantings, the crop coefficient is replaced by a landscape coefficient $\left(\mathrm{K}_{\mathrm{L}}\right)$ that results from the multiplicative combination of the species factor $\left(\mathrm{k}_{\mathrm{s}}\right)$, the density factor $\left(\mathrm{k}_{\mathrm{d}}\right)$, and the microclimatic factor $\left(\mathrm{k}_{\mathrm{mc}}\right)$ (compare COSTELlO et al. 2000, NOURI et al. 2013, 251). The method assigns numerical values to three major factors influencing evapotranspiration from mixed vegetation in urban landscapes, namely crop factors, environmental aspects, and management practices (equation 2)

Equation 2: $\mathrm{K}_{\mathrm{L}}=\mathrm{k}_{\mathrm{s}} \times \mathrm{k}_{\mathrm{d}} \times \mathrm{k}_{\mathrm{mc}}$

Multiplying the dimensionless landscape coefficient $\mathrm{K}_{\mathrm{L}}$ with reference evapotranspiration produces a reliable estimation of $\mathrm{ET}_{\mathrm{L}}$, i.e. urban landscape evapotranspiration (see equation $1)$. With the mapped area of private urban plots, where each polygon is classified as area dedicated to turf grass or trees and shrubs, the estimated evaporation water volumes can be calculated in a spatially explicit way. This can be juxtaposed with a calculation of net irrigation requirements (HOF \& WOLF 2014, SALVADOR et al. 2011) by converting from depth $(\mathrm{mm})$ to volume $\left(\mathrm{m}^{3}\right)$ to estimate the water volumes that are consumed outdoors on private urban plots for maintaining garden landscaping, and the benefits people obtain from this, i.e. the ecosystem services provided by private gardens (see figure 1).

\subsection{Assessment of Gardens' Contributions of Urban Landscaping and Bio- diversity Links}

Analyses of the contribution of gardens to landscaping of the urban environment are straightforwardly and closely linked to ecosystem structures and processes that are reflected in urban biodiversity patterns. As part of the ecological subsystem, the assessment of garden design captures path-dependencies and management decisions of the owners and tenants. With targeted mapping of vegetation units, the derived information on the extent and 
spatial configuration of urban green space as a unit of biodiversity conservation and management is further subdivided into service providing units that can be enriched by additional attributes, such as structural information, e.g. vertical extent of vegetation, foliage, edge density and quality. This distinction allows assessing habitat functions of gardens and urban green space for a wide array of species. Less mobile species tend to be sensitive to fragmentation, while the vertical distribution of the canopy and green volume are most valuable for predicting bird species richness and the capacity to sustain interior-dependent species. The structural complexity of man-made vegetation may generally enhance the habitat function for urban-avoiding groups like mammals, reptiles, and amphibians (GODDARD et al. 2009, KOWARIK 2011, STROHBACH et al. 2009). Constituting a large part of urban green spaces, private gardens can provide considerable biodiversity benefits. However, garden management has a scale-dependent impact, with the individual garden being much smaller than the unit of management needed to retain viable populations. Understanding the spatial configuration of urban green space, its ecological character, and the contribution of gardens to urban biodiversity is necessary for integrating it into city-wide biodiversity and climate change adaptation strategies.

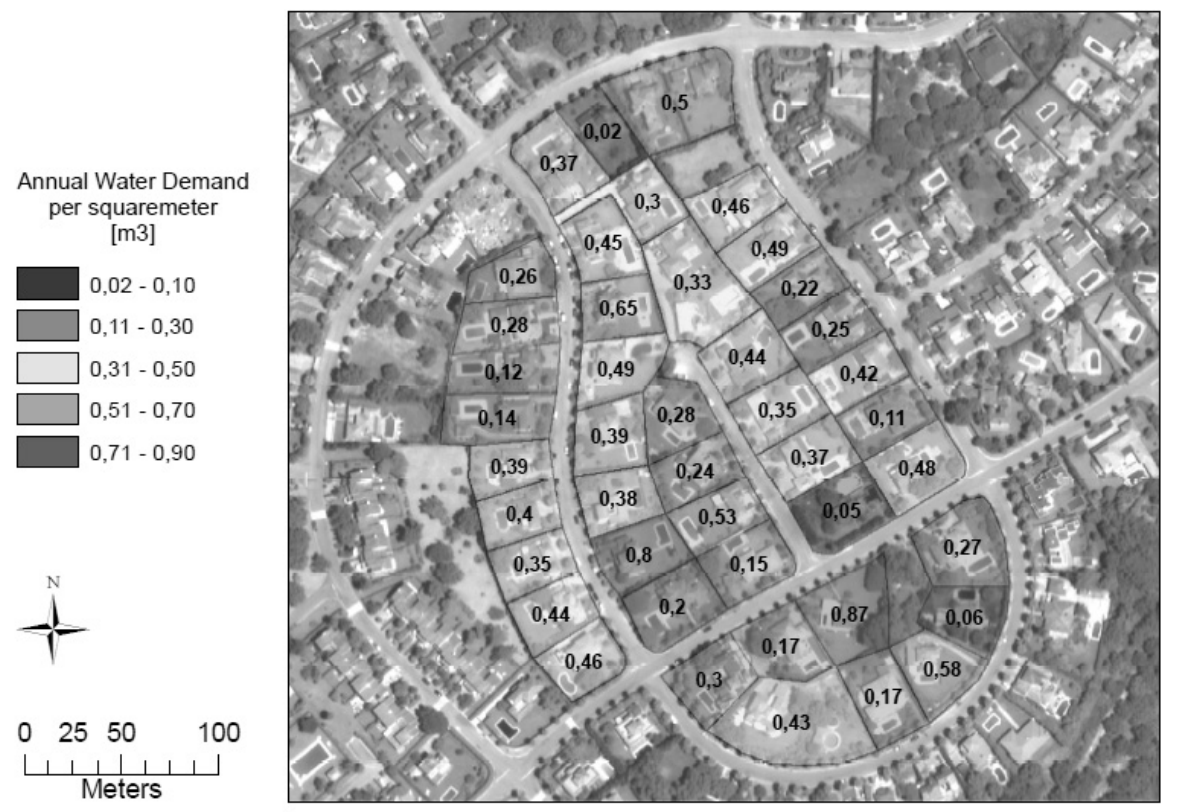

Fig. 1: Based on object-oriented targeted mapping of trees and shrubs, and turf grass, net irrigation requirements are assessed on a plot scale. Net irrigation requirements provide an estimation of the amount of water that should be partially or fully replaced by irrigation because it is water lost through urban landscape evapotranspiration (compare HOF \& WOLF 2014, NOURI et al. 2013) 
Another aspect is that private gardens are part of the 'novel urban ecosystems' that are increasingly coming into the focus of urban ecology (compare KOWARIK 2011). The author argues that it is time to consider the whole range of urban nature, because an exclusive focus on 'native nature' risks ignoring the benefits of the other aspects of urban nature emerging on profoundly altered sites or developing on sites shaped by horticulture (parks and gardens). There is evidence that individual urban habitat types across the whole spectrum, from pristine, to agricultural, horticultural, and urban-industrial can add a significant contribution to biodiversity conservation. Within cities, intensity of urban land use, habitat continuity, and management practices are likely crucial factors that determine biological richness (KOWARIK 2011). The targeted mapping and the conceptual extension of the modelling approach described in the following section are building blocks for modelling gardens based on systems science, and as social-ecological systems with associated urban ecosystem services.

\section{Modelling Gardens as Social-ecological systems - A Conceptual Extension of Previous Research}

Object-oriented remote sensing image analysis provides the targeted mapping for the assessment of garden irrigation requirements as a particular application domain of geodata in the urban context. The initial research focus and systems perspective is on land and vegetation cover and water use that interact with ecological functions and properties of gardens. This was outlined in the previous sections and was the focus of previous research (HoF \& WOLF 2014). The subsequent step is to analyse the linkages and feedback mechanisms between gardens as social-ecological systems and ecosystem services. For example, evapotranspirational cooling is a process that links a regulating ecosystem service with homeowner management decisions. Climate change models predict an increase of average temperatures and urban heat island effects. As densely built-up urban areas are particularly affected by such warming effects, private gardens may become important arenas in urban planning processes. A prerequisite for the inclusion in urban strategies is information about the nature of private gardens and their management, which is reflected in their design.

Following the modelling development approach and notation of SCHLÜTER et al. (2014) for dynamic models, that can serve as tools to explore social-ecological interactions, and adopting their point of view that the complexity of the studied social-ecological systems and the need to integrate knowledge, theories, and approaches from different disciplines pose considerable challenges for their development, a conceptual approach to modelling gardens as social-ecological systems is presented here. It is intended to illustrate the use of the socialecological systems and urban ecosystem services frameworks in conceptual modelling, not to provide a complete description of the modelling process and the model (compare SCHLÜTER et al. 2014).

The starting point for modelling gardens as social-ecological systems is the following research question: How do garden management decisions contribute to thermally-pleasant residential landscapes? This research question is addressed by looking first at analyzing the social-ecological interactions of garden management decisions and evapotranspirational cooling. To do so, model control variables, outcome indicators, and process relationships 
are described and represented by transferring the modelling development approach and notation of SCHLÜTER et al. (2014) to gardens as social-ecological systems.

\subsection{Operationalisation of the Research Question in the Model: Defining Outcome Indicators}

As indicated by the research question, it is of interest to understand how garden management decisions contribute to thermally-pleasant residential landscapes. The first step in operationalising the research question is thus to define 'homeowner Land/Vegetation-cover choices' and 'the landscaping reduction in air Temperature compared to a base case configuration of the garden landscaping' as the control variables, and 'garden evapotranspirational cooling' as the outcome indicator. Outcome indicators could also be normative, like irrigation performance, which would redirect the attention to measuring the variables net irrigation requirement and actual water applied to assess irrigation adequacy.

Outcome indicators are defined through indicator relationships that combine the variables that have to be measured to answer a specific research question. The outcome indicator is represented through a relation type that defines which variables determine the indicator (compare SCHLÜTER et al. 2014). The notation 'concept.variable', e.g. 'HO.Land/Vegetation-coverChoices', indicates that the variable after the period is attributed to the concept named before the period, e.g., the land and vegetation cover choices reflected in garden landscaping and design is attributed to the homeowner or tenant.

Outcome indicators:

- G.EvapotranspirationalCooling $\leftarrow$ (HO.Land/Vegetation-coverChoices,

L.ReductionInAirTemperatureComparedToBaseCaseConfiguration) (ecological function indicator)

- HO.IrrigationPerformance (normative, defines irrigation adequacy)

With abbreviations used: $\mathrm{HO}=$ homeowner or tenant; $\mathrm{G}=$ garden; $\mathrm{L}=$ landscaping

\subsection{Operationalisation of the Research Question in the Model: Defining Process Relationships}

Following and quoting SCHLÜTER et al. (2014, no pagination): "The second step in operationalizing the research question is specifying the variables that codetermine changes in the state of another variable and organize them in process relationships." Further, these authors describe how to analyse processes and outcomes in social-ecological systems with the defined process relationships (see SCHLÜTER et al. 2014, no pagination): "Process relationships formalize interactions between variables, e.g., the influence of an actor on the resource unit. The development of process relationships makes explicit which variables influence each other to determine the change of the coupled system over time. Process relationships thus provide a structured and transparent way to develop and communicate the structure of a model at a generic level. At this level we do not specify the relation itself, but only its type, which is the set of all possible relations. Specifying one particular relation would mean relating the variables through a specific statistical or mechanistic model, whereas SESF [Social-ecological systems frameworks, comment by the author] should remain theory-neutral, allowing for different models of the same process relationship. SESF therefore 
specifies a process relationship merely by naming the variables that participate in it. This suffices for making explicit the modeling decisions that we consider most crucial: which variables to include at what level of detail."

Here, the 'homeowner Land/Vegetation-cover choices' are codetermined by the effort homeowners are putting into garden management, and also by garden size and homeowner socioeconomic status (COOK et al. 2012). Additional process relationships could be the decision-making process of watering the garden and how homeowners are satisfied with the cooling effect and if this has a feedback on their gardening practices.

Process relationships are represented as mathematical (directed) relation types, with the influencing variables being the domain of the relation type, and the influenced variables its co-domain (compare SCHLÜTER et al. 2014). To represent that the variables homeowner effort, garden size, and homeowner socioeconomic status influence the variable 'homeowner Land/Vegetation-cover choices', the following process relationships are written:

Process relationships:

- $\quad$ GardenManagement: (HO.Effort, G.Size, HO.SocioeconomicStatus) $\rightarrow$ HO.Land/Vegetation-coverChoices

- WaterUseDecisionMaking: (AverageTemperature, HO.IrrigationTechnology, HO.PerceptionOfWaterCosts $) \rightarrow$ HO.IrrigationPerformance

- $\quad$ EvaluateBenefits: (HO.ThermalExpectation, HO.ThermalExposure) $\rightarrow$ HO.Satisfaction

With abbreviations used: $\mathrm{HO}=$ homeowner or tenant; $\mathrm{G}=$ garden; $\mathrm{L}=$ landscaping

The final step is formalizing process relationships in social-ecological system models. The result of the process of abstraction from private urban gardens as target social-ecological systems is a conceptual model, or case-specific framework that serves as the basis for data collection, design of the formal model, and its implementation and analysis (compare SCHLÜTER et al. 2014).

\section{Conclusion and Outlook}

Social-ecological systems and urban ecosystem services frameworks are connected to previous research, and are applied to guide a systematic and transparent process of model development to explore social-ecological interactions in private urban gardens. The limitation of approaches like these lie in the complexity of the studied systems, and they result from the need to integrate knowledge, theories, and approaches from different disciplines (compare SCHLÜTER et al. 2014). This poses considerable challenges for the model development. Thus, what is represented here is not a complete modelling approach, but a conceptual approach to modelling gardens as social-ecological systems using geodata. Future research will focus on the improvement of formal descriptions and definitions of outcome indicators and process relationships, and on formalizing process relationships in socialecological system models. 


\section{References}

BOYD, J. \& BANZHAF, S. (2007), What are ecosystem services? The need for standardized environmental accounting units. Ecological Economics, 63 (2-3), 616-626.

BoyD, D. S. \& FOODY, G. M. (2011), An overview of recent remote sensing and GIS based research in ecological informatics. Ecological Informatics, 6 (1, SI), 25-36.

Breuste, J., HaAse, D. \& ElmQuist, T. (2013), Urban Landscapes and Ecosystem Services. In: Wratten, S. D., SANDHU, H. \& Cullen, R. (Eds.): Ecosystem services in agricultural and urban landscapes. Wiley-Blackwell, Oxford, 83-104.

CoOK, E. M., HALl, S. J. \& LARSON, K. L. (2012), Residential landscapes as socialecological systems: a synthesis of multi-scalar interactions between people and their home environment. Urban Ecosystems, 15 (1), 19-52.

Costello, L., Matheny, N. \& Clark, J. (2000), A Guide to Estimating Irrigation Water Needs of Landscape Plantings in California The Landscape Coefficient Method and WUCOLS III**WUCOLS is the acronym for Water Use Classifications of Landscape Species. University of California Cooperative Extension California Department of Water Resources August WUCOLS 2000.

http://www.water.ca.gov/pubs/conservation/a_guide_to_estimating_irrigation_water_ne eds_of landscape plantings_in_california_wucols/wucols00.pdf.

Gaston, K. J., ÁvilA-JimÉnEz, M. L. \& EDMONDSON, J. L. (2013), Managing urban ecosystems for goods and services. Journal of Applied Ecology, 50 (4), 830-840.

Goddard, M. A., Dougill, A. J. \& Benton, T. G. (2010), Scaling up from gardens: biodiversity conservation in urban environments. Trends in Ecology \& Evolution, 25 (2), 90-98.

Gómez-Baggethun, E., Gren, A., Barton, D. N., Langemeyer, J., McPhearson, T., O'Farrell, P., Andersson, E., Hamstead, Z. \& Kremer, P. (2013), Urban ecosystem services. In: ElmQvist, Th., Fragkias, M., Goodness, J., GÜNeralP, B., Marcotullio, P. J., McDonald, R. I., Parnell, S., Schewenius, M., Sendstad, M., Seto, K. C. \& WILKINSON. C. (Eds.), Urbanization, biodiversity and ecosystem services. Challenges and opportunities: a global assessment, 175-251.

GRUNEWALD, K. \& BASTIAN, O. (Eds.) (2012), Ökosystemdienstleistungen. Konzept, Methoden und Fallbeispiele. Springer, Berlin/Heidelberg.

HaAse, D., Larondelle, N., Andersson, E., Artmann, M., Borgström, S., Breuste, J. et al. (2014), A Quantitative Review of Urban Ecosystem Service Assessments: Concepts, Models, and Implementation. Ambio, 43 (4), 413-433.

Hof, A. \& Wolf, N. (2014), Estimating potential outdoor water consumption in private urban landscapes by coupling high-resolution image analysis, irrigation water needs and evaporation estimation in Spain. Landscape and Urban Planning, 123 (0), 61-72. DOI: 10.1016/j.landurbplan.2013.12.010.

KOWARIK, I. (2011), Novel urban ecosystems, biodiversity, and conservation. Environmental Pollution, 159 (8-9), 1974-1983.

Milesi, C., Running S. W., Elvidge C. D., Dietz J. B., Tuttle B. T. \& Nemani R. R. (2005), Mapping and Modeling the Biogeochemical Cycling of Turf Grasses in the United States. Environmental Management, 36, 426-438.

Nouri, H., BEecham, S., KAZEMI, F. \& HASSANLI, A. M. (2013), A review of ET measurement techniques for estimating the water requirements of urban landscape vegetation. Urban Water Journal, 10 (4), 247-259. 
Polsky, C., Grove, J. M., Knudson, C., Groffman, P. M., Bettez, N., CavenderBARES, J. et al. (2014), Assessing the homogenization of urban land management with an application to US residential lawn care. In: Proceedings of the National Academy of Sciences, 111 (12), 4432-4437.

Salvador, R., Bautista-CAPetillo, C., \& PlayÁn, E. (2011), Irrigation performance in private urban landscapes: A study case in Zaragoza (Spain). Landscape and Urban Planning, 100 (3), 302-311.

SchlÜter, M., Hinkel, J., Bots, P. W. G. \& Arlinghaus, R. (2014), Application of the SES framework for model-based analysis of the dynamics of social-ecological systems. Ecology and Society, 19 (1), 36. http://dx.doi.org/10.5751/ES-05782-190136.

Strohbach, M. W., HAASE, D. \& KABISCH, N. (2009), Birds and the city: urban biodiversity, land use, and socioeconomics. Ecology and Society, 14 (2, 31).

Wolf, N. (2013), Object Features for Pixel-based Classification of Urban Areas Comparing Different Machine Learning Algorithms. Photogrammetrie - Fernerkundung - Geoinformation, 2013 (3), 149-161. doi:10.1127/1432-8364/2013/0166. 